+103 EARLY DETECTION OF CONDUCT ION SYSTEM ABNORMALITIES R. Gow MD, P. Hesslein MD, C. Finlay BSC, G. Trusler MD, W. Williams MD, R. Rowe MD The Hospital for Sick Children, Toronto, CANADA

The association of symptomatic and fatal dysrhythmias after Mustard's operation requires early detection and characterization of CSA to identify susceptible children and suggest surgical modifications. We performed bedside electrophysiologic studies (EPS) on 21 infants with single transposition on days 1,3 and 8 following Mustard repair using epicardial atrial and ventricular temporary pacing wires. Pre-operative studies were performed in 12 subjects. Median age at study was 8 mos (range $3-15$ mos); 11 of 21 had prior Blalock-Hanlon septectomy (BHS). Sinus node dysfunction (SND) was documented in 2/11 pre-operatively (both had BHS), and $15 / 21$ postoperatively; $9 / 17$ (6 with BHS) had SND persisting to day 8. AV node dysfunction (AVND) developed postoperatively in $4 / 21$. Changes in retrograde VA conduction were either transient $(7 / 21)$ or persistent $(14 / 21) .4$ subjects had inducible supraventricular tachydysrhythmias (STD) with three subsequently developing spontaneous STD requiring chronic therapy. No child without inducible STD has yet had spontaneous STD. We conclude that early bedside EPS will document CSA and identify those at risk for later symptomatic dysrhythmias. SND is prevalent in this series, and AVND is surprisingly common. The finding of inducible STD appears to be particularly predictive of subsequent course.

*supported by Ontario Heart and Stroke Foundation

RESPONSE TO EXERCISE AFTER FONTAN PROCEDURE. Geordie

0104 . Grant, Anthony L. Mansel1, Robert P. Garofano, Constance J. Hayes, Frederick 0 . Bowman, James $\underline{R}$. Malm and Welton M. Gersony. Columbia Univ. Coll. of Physicians \& Surgeons, Babies Hospital, Department of Pediatrics, New York. Previous studies demonstrating maldistribution of pulmonary blood flow in patients who had undergone Fontan procedures (FP) predict high physiologic dead space during exercise. We used noninvasive exercise testing to assess gas exchange in 5 patients age 10-19, compared to 11 age and sex matched controls. Oxygen saturation was measured by ear oximetry at rest and after exercise. The ventilatory equivalents for oxygen (Ve/V02) and carbon dioxide ( $\mathrm{Ve} / \mathrm{FCO} 2)$ were measured during progressive exercise and mixed expired $\mathrm{pCO} 2(\mathrm{PeCO} 2)$ and end-tida1 pCO2 (PetCO2) were measured during steady state exercise on a cycle ergometer. We obtained the following results:

\begin{tabular}{|c|c|c|c|}
\hline$\dot{\mathrm{Ve}} / \dot{\mathrm{V}} 2$ & $\frac{\mathrm{FP}}{41^{ \pm}}$ & $\frac{\text { Controls }}{24 \pm 2}$ & $\frac{\text { Significance }}{\mathrm{p}<0.001}$ \\
\hline$\dot{\mathrm{Ve}} / \dot{\mathrm{V} C O} 2$ & $47 \pm 14$ & $27 \pm 2$ & $\mathrm{p}<0.001$ \\
\hline PeC02, torr & $17.8 \stackrel{+}{+} .5$ & $26.9 \pm 2.8$ & $p<0.001$ \\
\hline PetCO2, torr & $28.5-5.2$ & $39.1 \pm 2.0$ & $p<0.001$ \\
\hline
\end{tabular}

In addition, the patients had a mean oxygen saturation of $89-6 \%$ at rest and desaturated further during exercise $\left(8 \pm_{11}^{ \pm}, \mathrm{p}<0.05\right)$. These data show high ventilation for $\mathrm{O}_{2}$ consumption and $\mathrm{CO}_{2}$ proThese data show high ventilation for $\mathrm{O}_{2}$ consumption and $\mathrm{CO}_{2}$ production, low expired $\mathrm{CO}_{2}$ concentrations and oxygen desaturation during exercise. The results strongly indicate elevated physio-
logic dead space and ventilation perfusion mismatch consistent with maldistribution of pulmonary blood flow.

THE EFFECT OF RIGHT TO LEFT INTRACARDIAC SHUNTING ON ARTERIAL LIDOCAINE LEVELS IN A CANINE MODEL William Henry, Daniel Cas to, Blair Keagy, Enrique Criado, Jose Ferreiro, Benson Wilcox (Spon. by Thomas F. Boat) University of North Carolina Schools and Surgery, Chape $1 \mathrm{Hi}$ l], N.C.

Because lidocaine uptake occurs in the lung, a reduction in effective pulmonary blood flow (Qep) would be expected to raise serum concentrations. To test this hypothes is, a right to left atrial shunt ( $40-50 \%$ of the basal cardiac output) was developed
in each of 7 adult mongre 7 dogs by connecting cannulae inserted in each of 7 adult mongre 1 dogs by connecting cannulae inserted Eight additional dogs served as controls. Following a $4 \mathrm{mg} / \mathrm{kg}$ intravenous bolus injection of lidocaine, central venous and aortic pressures, cardiac output, and an arterial blood sample were obtained at $0,3,5,8,10,15,20,30,40,50$, and 60 minutes. Serum 7 idocaine concentrations $(L)$, were determined using a homogeneous enzyme assay (EMIT). Cardiac output, pressures, and acid-base status were not significantly different for the 2

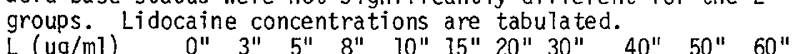
\begin{tabular}{llllllllllll}
$L$ & $(\mathrm{ug} / \mathrm{m} 1)$ \\
Control $(\mathrm{n}=8)$ & $0^{\prime \prime}$ & $3^{\prime \prime}$ & $5^{\prime \prime}$ & $8^{\prime \prime}$ & $10^{\prime \prime}$ & $75^{\prime \prime}$ & $20^{\prime \prime}$ & $30^{\prime \prime}$ & $40^{\prime \prime}$ & $50^{\prime \prime}$ & $60^{\prime \prime}$ \\
\hline & 4.5 & 3.4 & 2.4 & 2.2 & 7.5 & 1.3 & 1.7 & 1.0 & 0.9 & 0.8
\end{tabular} $\begin{array}{lllllllllllll}\text { Control } & (n=8) & 0 & 4.5 & 3.4 & 2.4 & 2.2 & .5 & .3 & .1 & 1.0 & 0.9 & 0.8 \\ \text { Shunt } \quad(n=7) & 0 & 5.9 & 4.3 & 3.0 & 2.6 & 2.0 & 1.8 & 1.4 & 1.3 & 1.2 & 1.1\end{array}$ $\begin{array}{lrrrrrrrrrr}\% \text { increase } & 31 & 26 & 25 & 18 & 33 & 38 & 27 & 30 & 33 & 38 \\ \mathrm{p} & .03 & .11 & .05 & .24 & .07 & 14 & .13 & .08 & 04 & .005\end{array}$

These results indicate that with an acute $40-50 \%$ reduction in Qep, arterial lidocaine levels are elevated from $18-38 \%$. Therefore, patients with right to left intracardiac shunting may be at increased risk for developing lidocaine toxicity, and an initial dosage reduction in those patients is appropriate.
106 TH COMPLETB TRANSPOSITION OF THE GREAT ARTERIRS

James C. Huhta, Sanaa A. Abdallah, Michael R. Nihill, Daniel J. Murphy (Spon. by Ralph D. Feigin). Baylor College of Medicine, Texas Children's Hospital, Department of Pediatrics, Houston.

Quantitative assessment of hemodynamics in neonates with complete transposition (TGA) was performed using two-dimensional (2D) directed pulsed Doppler echocardiography. Both the aortic valve (RV) and pulmonary valve (LV) flow velocities were obtained in 5 neonates before and during a 1 hour infusion of prostaglandin $E_{1}$ (PGE) at $0.1 \mathrm{mcg} / \mathrm{kg} / \mathrm{min}$ following balloon atrial septostomy. Ductus arteriosus (DA) size by $2 \mathrm{D}$ imaging increased in all and pulmonary to aortic shunting was excluded by Doppler sampling in DA. Stroke volume changes were estimated by the product of the Doppler time-velocity integral (TVI) and heart rate $(\mathrm{cm} / \mathrm{min})$. Doppler systolic time intervals (PEP/ET) were calculated.

\begin{tabular}{|c|c|c|c|c|c|c|}
\hline \multirow[b]{2}{*}{$n=8$} & \multirow[b]{2}{*}{$\mathrm{HR}$} & \multicolumn{2}{|c|}{ TVI $\times H R$} & \multirow{2}{*}{$\frac{L V \times H R}{R V \times H R}$} & \multicolumn{2}{|c|}{ PEP/ET } \\
\hline & & $\overline{\mathrm{LV}}$ & RV & & $\overline{\mathrm{LV}}$ & $\mathrm{RV}$ \\
\hline Off PGE & 135 & 2122 & 1125 & 1.89 & 0.30 & 0.52 \\
\hline On PGE & 148 & 1767 & 1466 & 1.21 & 0.35 & 0.42 \\
\hline $\mathrm{p}$ value & $<0.05$ & $<0.005$ & $<0.005$ & $<0.005$ & 0.1 & 0.1 \\
\hline
\end{tabular}

LV stroke volume decreased while RV stroke volume increased. The ratio of LV to RV stroke volume consistently decreased. An increase in $\mathrm{LV}$ and decrease in RV systolic time intervals did not reach a significant level.

Conclusions: PGE in neonates with TGA results in decreased LV stroke volume. Enhanced intraatrial mixing in TGA with PGE may be mediated, in part, by decreased LV filling.

\section{PULSED DOPPLER DIAGNOSIS OF ATRIOVENTRICULAR VALVE INSUFFICIENCY IN UTERO} James C. Huhta, Daniel J. Murphy, Robert J. Carpenter (Spon. by Ralph D. Feigin). Baylor College of Medicine, Texas Children's Hospital, Department of Pediatrics, Houston.

A trioventricular valve insufficiency (AVVI) has been suggested as a cause for nonimmune hydrops in utero. Pulsed 2-D-directed Doppler echocardiography was utilized for the detection of AVVI in 41 fetuses ranging in gestational age from 16-39 weeks. AVVI was diagnosed by a systolic velocity in either atria of greater than 1 meter per second.

AVVI was present in $5 / 41$ fetuses $(12 \%)$ and confirmed after birth in $3 / 3$. Of 22 fetuses at risk for congenital heart disease but found to be normal, one had AVVI (5\%). Of 11 patients with fetal dysrhythmia, $2 / 2$ with complete heart block ( 1 normal and 1 with AV canal) had intermittent AVVI, and 7 with premature atrial contractions and 2 with atrial tachycardia had none. Of 6 patients with abnormal cardiac findings, 2 had AVVI (1 with endocardial fibroelastosis and bilateral AVVI, and 1 with cerebral arteriovenous malformation) while there was no AVVI in 4 patients with VSD including 1 with hydrops. Two patients with a normal heart and hydrops had no AVVI.

Conclusions: (1) AVVI occurs in utero and may be diagnosed by pulsed Doppler echocardiography. (2) AVVI may be present in normals, in fetuses with congenital heart block with or without heart disease, and is not present in all forms of nonimmune hydrops fetalis.
0108 CALCIUM BLOCKERS AFTER B-BLOCKADE IN CONSCIOUS

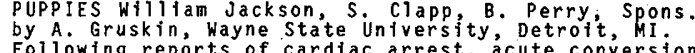
Following reports of cardiac arrest, acute conversion
therapy with verapamil is contraindicated in childen on chronic propranlol for recurrent sVT The exact hemodynamic changes prodren or awake, instrumented immature animals. We proposed to docimitarly effective calcilum-blocking agent, diltiazem, potent-
iafiy of use in pediatric patients. Fourteen puppies were chrof use in pediatric patients. Fourteen pupples were
chronically instrumented for: aortic flow(co); regional LV
shortening(SF); pressures--carotid(MBP), pulmonary(PAP), and

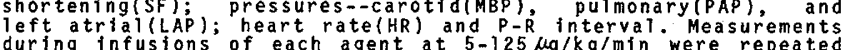

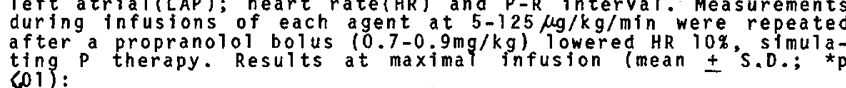

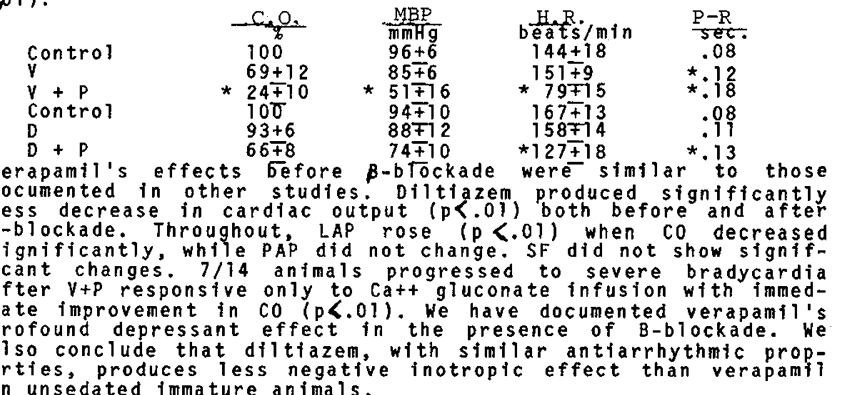

